\title{
Metaplastic Breast Cancer
}

\author{
Halil Türkan, M. Şehsuvar Gökgöz, N. Serhat Parlak \\ Department of General Surgery, Uludağ University Faculty of Medicine, Bursa, Turkey
}

\begin{abstract}
Metaplastic Breast Cancer (MBC) is a term referring to a heterogeneous group with malignant epithelial and mesenchymal tissue components. $\mathrm{MBC}$ is a rare disease, accounting for $0.2 \%$ of all breast cancers. Most $\mathrm{MBC}$ are triple negative cancers with poor prognosis and an aggressive clinical course. Herein, we aimed to present a 74-year-old patient with metaplastic breast cancer along with clinical, radiologic and pathologic properties.
\end{abstract}

Keywords: Metaplastic Breast Cancer, malignant epithelial tumor, mesenchymal tumor

\section{Introduction}

Metaplastic Breast Cancer (MBC) constitutes $0.2 \%$ of all breast cancers and was first described in 1974 by Huvos et al (1). It is usually seen in women over the age of 50 and they usually present with a large tumor size. There are no specific radiologic findings. Wargotz et al. (2) grouped MBC into five classes:

1. Carcinosarcoma,

2. Matrix-producing carcinoma,

3. Spindle-cell carcinoma,

4. Squamous cell carcinoma,

5. Osteoclastic giant cell carcinoma

Metaplastic Breast Cancer has been re-classified by the World Health Organization (WHO) in 2012 into seven groups. The detailed classification is presented in the following section of our article (Table 1). In the literature, they are reported to have a more aggressive course and worse prognosis as compared to ductal carcinoma (3).

\section{Case Presentation}

A 74-year-old female patient was referred to our breast surgery unit due to a lump on her right breast that has been noticed 2 months ago and has been rapidly growing since then. There was no family history of breast cancer. On physical examination, there was a $10 \mathrm{~cm}$ lobulated mass in the right breast extending from approximately $2 \mathrm{~cm}$ superior to the nipple to the upper quadrants, accompanied by necrosis and ulceration of the overlying skin (Figure 1).

Mammography revealed an oval, 81×62 mm in size, regular bordered mass in the right breast upper-middle segment. In addition, a second irregular bordered, $35 \times 32 \mathrm{~mm}$ in size mass was superposed over this lesion (Figure 2). Ultrasound imaging showed an irregular bordered hypoechoic lesion, $22 \times 25 \mathrm{~mm}$ in size, $3 \mathrm{~cm}$ away from the nipple at 12 o'clock position of her right breast.

Ultrasound guided tru-cut biopsy of the lesion was performed, which revealed metaplastic carcinoma (with squamous carcinoma component). The patient who did not manifest any distant metastases underwent modified radical mastectomy.

The macroscopic evaluation displayed a $16.5 \times 11 \mathrm{~cm}$ in diameter mastectomy specimen with skin ellipse that is $18 \times 12 \times 4.5 \mathrm{~cm}$ in size, and a $9 \times 8.5 \times 4.5 \mathrm{~cm}$ in size, gray-yellow-white on cut-surface, hard tumor with ulcerations that protrudes $2.7 \mathrm{~cm}$ out of the skin. 


\section{Table 1. Metaplastic breast carcinoma WHO 2012 classification}

1- Low grade adenosquamous carcinoma

2- Fibromatous-like metaplastic carcinoma

3- Squamous cell carcinoma

4- Spindle cell carcinoma

5- Metaplastic carcinoma with mesenchymal differentiation

a) Chondroid differentiation

b) Osseous differentiation

C) Other types

6- Mixed type metaplastic carcinoma

7- Myoepithelial carcinoma

WHO: World Health Organization

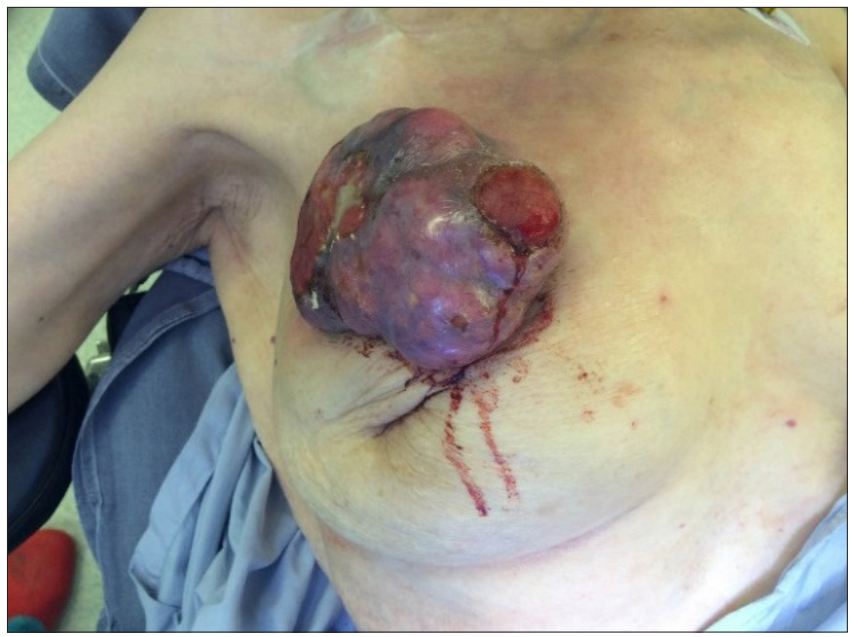

Figure 1. Preoperative image of the breast
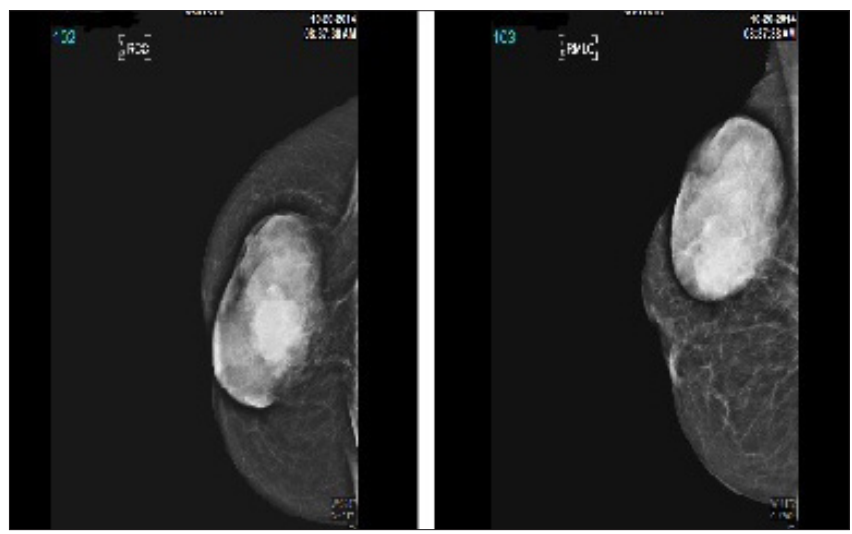

Figure 2. Mammography; oval shaped, regular bordered lesion and a second superposed irregular bordered lesion

On histopathologic examination: Metaplastic carcinoma (with squamous cell carcinoma component), tumor size: $9 \times 8,5 \times 4,5 \mathrm{~cm}$, GRADE: 3 (according to modified Bloom Richardson, tubule formation: 3, Pleomorphism: 3, Mitosis: 3) ER (Estrogen Receptor): 70\% weak positive, PR (Progesterone Receptor): Negative, CerbB2: Nega-
E-Cadherin: Positive, CK5 / 6: Focal positive, EGFR (Epidermal Growth Factor Receptor): Weak-positive, CD31: Positive in endothelial and tumor cells.

Axillary dissection material revealed 2 metastatic lymph nodes and 24 benign reactive hyperplasia.

There were no postoperative complications. The patient received radiotherapy $(\mathrm{RT})+$ hormonotherapy $(\mathrm{HT})$ according to the multidisciplinary meeting decision.

The re-evaluation of all these findings; initially noticing a palpable breast lesion, which expanded into a lesion with skin ulceration and immunohistochemical CK5/6 positivity excluded skin squamous carcinoma, and led to a diagnosis of metaplastic breast cancer (with squamous component). An informed consent was obtained and the patient was notified of the case report.

\section{Discussion and Conclusions}

Metaplastic Breast Cancer was re-classified by the WHO in 2012. It is usually detected in the $5^{\text {th }}$ decades. Due to their propensity for rapidgrowth, they are generally large on admission (tumor diameter 1-20 $\mathrm{cm}$ ). A tumor size less than $4 \mathrm{~cm}$ is accepted as a good prognostic factor (4). Several cases originating from fibroadenoma or phyllodes cystosarcoma have been reported (5). Axillary lymph node metastasis is rare in this entity, $25-30 \%$. Lymph node involvement is less than that of adenocarcinoma $(6,7)$. The risk of distant metastases is higher than that in adenocarcinoma. The lungs and bones are the most common sites for distant metastases.

Although there are no specific findings on mammography and ultrasound, radiologic findings vary depending on the components contained in the lesion. On mammography, they are usually visualized as well-defined, lobular-contoured masses. On US, they are seen as a mass with cystic components showing complex internal echogenicity. On MRI, they appear iso-hypointense compared to glandular tissue on T1-weighted, and hyperintense depending on the mucoid content and necrotic component on T2-weighted images (8).

Histopathologically they are within the group of triple negative tumors. They stain negative for HER2 and hormone receptors (ER, PR), and cerbB2 oncogene expression is low $(9,10)$. The p63 gene that plays a significant role in epithelial proliferation and differentiation was reported to be significantly high in metaplastic breast carcinomas. $\alpha \mathrm{B}$-crystalline known as the heat-shock protein was also suggested as a marker for metaplastic breast carcinomas. The high expression of this protein in the tumor tissue indicates a poor prognosis (11).

Although it is reported that modified radical mastectomy and breastconserving therapy both result in identical results in appropriate cases, there is an inclination for performing modified radical mastectomy due to the large tumor size and the high rate of local recurrence. The 5 -year survival rate is $40 \%$, and local recurrence rate is reported to be $35-62 \%$ in the first $2-5$ years (12). For adjuvant treatment, anthracycline containing chemotherapy regimens are considered to be more effective (13). Radiotherapy has an important role in adjuvant treatment. MBC spreads by lymphatic and hematogenous routes. Hematogenous spread is more frequent especially in the sarcomatoid spectrum dominant types. In various retrospective studies, tumor size is reported to be a more important prognostic criterion than lymph node involvement, and that the type of metaplasia is not correlated with prognosis. 
In conclusion, this is a rare type of tumor and in accordance with the literature, our patient presented with rapid growth and a large tumor size. They usually present with larger tumor size, less lymph node involvement, higher histologic grade and less hormone receptor positivity as compared to invasive ductal carcinoma. Sanguinetti et al. (14) indicated that tumor size has a major effect on the outcome. Its treatment should be more aggressive than invasive ductal carcinoma because of the higher rates of local recurrence and metastasis (15). The 5 -year survival rate is $40 \%$, and the prognosis is dismal.

Informed Consent: Written informed consent was obtained from patients who participated in this study.

Peer-review: Externally peer-reviewed.

Author Contributions: Concept - H.T.; Design - H.T.; Supervision H.T., M.Ş.G.; Materials; Data Collection and/or Processing - H.T.; Analysis and/or Interpretation - H.T., M.S..G.; Literature Review H.T., N.S.P.; Writing - H.T., N.S.P.; Critical Review - H.T., M.Ş.G.

Conflict of Interest: No conflict of interest was declared by the authors.

Financial Disclosure: The authors declared that this study has received no financial support.

\section{References}

1. Huvos AG, Lucas JC, Foote FW. Metaplastic breast carcinoma: Rare form of mammary cancer. NY State J Med 1973; 73:1078-1082. (PMID: 4348806)

2. Wargotz ES, Norris HJ. Metaplastic carcinomas of the breast I: Matrix-producing carcinoma. Human Pathol 1989; 20:628-635. (PMID: 2544506) [CrossRef]

3. Luini A, Aguilar M, Gatti G, Fasani R, Botteri E, Brito JA, Maisonneuve P, Vento AR, Viale G. Metaplastic carcinoma of the breast, an unusual disease with worse prognosis: the experience of the european Institute of Oncology and review of the literature. Breast Cancer Res Treat 2007; 101:349-353. (PMID: 17009109) [CrossRef]
4. Oberman HA. Metaplastic carcinoma of the breast. A clinicopathologic study of 29 patients. Am J Surg Pathol 1987; 11:918-929. (PMID: 2825549) [CrossRef]

5. Rosen PP (Ed). Rosen's breast pathology. Philadelphia; Lippincott Williams\&Wilkins, 2001: p. 425-453.

6. Carter MR, Hornick JL, Lester S, Fletcher CD. Spindlecell (sarcomatoid) carcinoma of the breast: a clinicopathologic and immunohistochemical analysis of 29 cases. Am J Surg Pathol 2006; 30:300-309. (PMID: 16538049)

7. Karaman N, Yılmaz KB, Kebat T, Hüseyinova S, Özaslan C. 16 yaşında bir bayan hastada memenin metaplastik karsinomu. J Breast Health 2007; 1:35-37.

8. Günhan-Bilgen I, Memis A, Üstün EE, Zekioglu O, Özdemir N. Metaplastic carcinoma of the breast: clinical, mammographic, and sonographic finding swith histopathologic correlation. AJR 2002; 178:1421-1425. [CrossRef]

9. Al Sayed AD, El Weshi AN, Tulbah AM, Rahal MM, Ezzat AA. Metaplastic carcinoma of the breast clinical presentation, treatment results and prognostic factors. Acta Oncol 2006; 45:188-195. (PMID: 16546865) [CrossRef]

10. Hennessy BT, Giordano S, Broglio K, Duan Z, Trent J, Buchholz TA, Babiera G, Hortobagyi GN, Valero V. Biphasic metaplasti csarcomatoid carcinoma of the breast. Ann Oncol 2006; 17:605-613. (PMID: 16469754) [CrossRef]

11. Sitterding SM, Wiseman WR, Schiller CL, Luan C, Chen F, Moyano JV, Watkin WG, Wiley EL, Cryns VL, Diaz LK. AlphaB-crystallin: A novel marker of invasiv basal-like and metaplastic breast carcinomas. Ann Diagn Pathol 2008; 12:33-40. (PMID: 18164413) [CrossRef]

12. Rayson D, Adjei AA, Suman VJ, Wold LE, Ingle JN. Metaplastic breast cancer: prognosis and responseto systemic therapy. Ann Oncol 1999; 10:413-419. (PMID: 10370783) [CrossRef]

13. Buzdar AU, Valero V, Theriault RL. Pathological complete response to chemotherapy is related to hormone receptor status. San Antonio Breast Cancer Symposium 2003; Abstr 302.

14. Sanguinetti A, Lucchini R, Santoprete S, Farabi R, Fioriti L, Bistoni G, Metaplastic carcinoma of the breast: Treatment, results and prognostic factors based on international literature. Ann Ital Chir 2014; 85:109-113. (PMID: 24195912)

15. Pezzi CM, Patel-Parekh L, Cole K, Franko J, Klimberg VS, Bland K. Characteristics and treatment of metaplastic breast cancer: analysis of 892 cases from the National Cancer Data Base. Ann Surg Oncol 2007; 14: 166-173. (PMID: 17066230) [CrossRef] 